\title{
The delivery of the ReWork-Stroke program: A process evaluation
}

\author{
Ulla Johansson $^{\mathrm{a}}$, Annika Öst Nilsson ${ }^{\mathrm{a}, \mathrm{b}}$, Annie Hansen Falkdal ${ }^{\mathrm{c}}$, Lena von Koch ${ }^{\mathrm{d}, \mathrm{e}}$, \\ Therese Hellman ${ }^{\mathrm{f}}$ and Gunilla Eriksson ${ }^{\mathrm{b}, \mathrm{g}, *}$ \\ ${ }^{a}$ Centre for Research \& Development, Uppsala University, Gävle, Sweden \\ ${ }^{\mathrm{b}}$ Department of Neurobiology, Care Sciences and Society, Division of Occupational Therapy, \\ Karolinska Institutet, Huddinge, Sweden \\ ${ }^{\mathrm{c}}$ Department of Community Medicine and Rehabilitation, Occupational Therapy, Umeå University, \\ Umeå, Sweden \\ ${ }^{\mathrm{d}}$ Neuro Theme, Karolinska University Hospital, Stockholm, Sweden \\ ${ }^{\mathrm{e}}$ Department of Neurobiology, Care Sciences and Society, Division of Family Medicine and Primary Care, \\ Karolinska Institutet, Huddinge, Sweden \\ ${ }^{\mathrm{f}}$ Department of Medical Sciences, Occupational and Environmental Medicine, Uppsala University, Uppsala, \\ Sweden \\ ${ }^{\mathrm{g}}$ Department of Neuroscience, Rehabilitation Medicine, Uppsala University, Uppsala, Sweden
}

Received 28 March 2020

Accepted 15 January 2021

\begin{abstract}
.
BACKGROUND: The ReWork-Stroke program was developed to meet the need for a person-centered rehabilitation program addressing return to work after stroke and was provided by occupational therapists (OTs).

OBJECTIVE: To gain knowledge on the implementation process of the ReWork-Stroke program, the mechanisms of impact, and the contextual factors that might have affected the process.

METHODS: A case study design was used. Data were collected by interviews with two ReWork-Stroke providers and their logbooks of 13 clients. Content analysis was applied.

RESULTS: The ReWork-Stroke program varied in duration (12-48 weeks) and was largely implemented according to plan regarding components and how they were provided. It was mostly delivered at the workplace. Mechanisms of impact were building alliances with clients, providing intervention at the workplace, informing about stroke, assigning co-workers as tutors for clients, and collaboration between stakeholders.

CONCLUSIONS: The ReWork-Stroke program can be implemented according to plan and is a flexible person-centered program in which stakeholders, coordinated by an OT, plan and take actions, mostly at the workplace, for the client's return to work. A key factor was recognizing the current work ability after stroke. Further program development includes a more structured evaluation and technical solutions for supporting stakeholders.
\end{abstract}

Keywords: Occupational therapy, rehabilitation, vocational, stroke, coordinator, ABI

\footnotetext{
*Address for correspondence: Gunilla Eriksson, Department of Neurobiology, Care Sciences and Society, Division of Occupational Therapy, Karolinska Institutet, Alfred Nobels Allé 23, 4th floor, SE-14183 Huddinge, Sweden. Tel.: +46702 2169 24; E-mail: gunilla.eriksson@ki.se.
}

\section{Introduction}

There is a lack of evidence-based rehabilitation programs for return to work (RTW) for people with stroke [1]. Only a couple of evidence-based personcentered rehabilitation programs addressing RTW after stroke exist [2, 3]. However, none of these are customized to the social insurance system and 
governmental responsibilities involved in the RTW process in Sweden. A systematic review [1] revealed that workplace adjustments and work-directed interventions are important to succeed in RTW after stroke. Furthermore, a recent systematic review of workplace interventions showed small but positive significant effect on work ability [4]. Involving the workplace, employer, and co-worker early after stroke as well as having a period of work trial are found to be significant in vocational rehabilitation programs. As more than one-third of those who have a stroke below the age of 65 do not return to work in Sweden [5, 6], a person-centered rehabilitation program for return to work was developed: the ReWork-Stroke program.

The development of ReWork-Stroke started with clinical experience and an overview of existing knowledge as recommended in the Medical Research Council guidelines for developing and evaluating complex interventions [7]. Further, experiences of RTW for persons with stroke and acquired brain injuries were gathered from stakeholders that usually are involved in the RTW process for people that are on sickness absence, as well as experiences from people who had had stroke in working age [8]. These stakeholders are healthcare service, employers, the Swedish Social Insurance Agency (SSIA) and the Swedish Public Employment Office. The knowledge constituted a base for the program development.

The ReWork-Stroke program consists of two phases: a phase of planning for RTW, which can vary in length, and a work trial phase limited to three months according to SSIA regulations. The starting point of the ReWork program was defined by the individual's desire and readiness for work related rehabilitation. Hence, the start was not a determined point in time after stroke as the rehabilitation process is not linear and differs between individuals. The program is to be provided and coordinated by a person, who has skills in analysis of performance levels in various activities including work tasks, preferably an occupational therapist (OT) and in addition extensive knowledge in stroke and vocational rehabilitation. A position in a specialized brain injury rehabilitation team can be of great value for the provider as it allows for early identification of candidates for the program and to liaise with the stakeholders. The OT should prepare the client and the employer for the work trial, provide information and coordinate relevant stakeholders during the ReWork-Stroke program, and conduct recurrent visits to the workplace to continuously meet with all involved. The aims for the workplace are to be the arena for sharing knowledge and, for those involved, to co-create work ability and possibly work re-entry. More detailed information concerning the ReWork-Stroke program is presented elsewhere [9]. The ReWork-Stroke program has been tried out in a group of people who worked before their stroke. Their experiences of participating in ReWorkStroke have previously been reported [10], as have the experiences of their co-workers and managers [11]. The persons with stroke as well as the co-workers valued the support from the coordinating OTs, who facilitated open and recurring communication that eased the RTW process.

In the development and testing phase of a new complex intervention, it is recognized that a process evaluation is an essential part [12] in order to be able to understand the functioning of the intervention. A process evaluation examines the mechanisms of impact, the contextual factors and the implementation of the intervention [12]. In the present study, the focus is on the quality and quantity of what was delivered in the ReWork-Stroke program as a basis for further development/refinement [13]. Various factors can impact how clinicians-in this case the OTs-implement a new intervention, such as their use of knowledge, how they interact with and respond to those involved during the implementation process, and how they relate to the various contexts in which the implementation of the intervention takes place [12].

\subsection{Objective}

This study aims to gain knowledge on the implementation process of ReWork-Stroke, the mechanisms of impact and the contextual factors that might have affected the process. This evaluation has two parts. First, the focus is on the delivery of the ReWorkStroke program in terms of where, when, and how ReWork-Stroke was provided and distributed over time, and how much time was used. Secondly, the OTs' understanding of the mechanisms of impact in the intervention is explored, as well as the experience of providing the intervention to the clients with stroke.

\section{Methods}

\subsection{Design}

This process evaluation used a case study design [14], as the aim was to gain knowledge on the 
implementation of the ReWork-Stroke program in depth-an endeavor that is too complex for a survey or experimental design [14]. The case consists of the functioning of the person-centered rehabilitation program ReWork-Stroke, how it was provided, and the experience of providing the program. Triangulation of multiple data sources have been used, including semi-structured interviews, logbooks on the intervention provided, and quantitative process data as to how and where the intervention was given.

\subsection{Participants}

The participants in this study were the two OTs who provided the ReWork-Stroke program to 13 clients. The two OTs had extensive clinical experience of rehabilitation after acquired brain injury in outreach rehabilitation teams ( 25 and 14 years, respectively). The clients were recruited between December 2014 and November 2015 from the teams in which the two OTs were members. Demographic information on the clients is given in Table 1. Of those 13 clients eight returned to paid work with different levels of working hours from $25-75 \%$ of full time. Four participants were still in work-trial at the latest follow up (nine months after beginning of work trial) and for one participant the joint decision was to not return to work due to the severity of the consequences of stroke.

Table 1

Demographic characteristics of the clients $(n=13)$

\begin{tabular}{lc}
\hline Gender: male/female $(n)$ & $8 / 5$ \\
\hline Age at stroke onset; & $50 / 5.7 / 40-57$ \\
$\quad$ mean/SD/range & \\
Married/single $(n)$ & $9 / 4$ \\
Stroke severity; mild/moderate $(n)$ & $10 / 3$ \\
Months from stroke & $8.8 / 4.5-19$ \\
$\quad$ onset to inclusion in & \\
$\quad$ ReWork-Stroke; mean/range & \\
Professions (n) & \\
- Assistant nurse & 2 \\
- Craftsman & 3 \\
- IT consultant & 2 \\
- Teacher & 3 \\
- Security guard & 1 \\
- Manager & 1 \\
- Forwarding agent & 1 \\
Consequences of stroke (n) & \\
- Fatigue & 8 \\
- Cognitive impairment & 7 \\
- Motor impairment & 7 \\
- Visual impairment & 4 \\
- Aphasia & 4 \\
\hline
\end{tabular}

\subsection{Data collection}

Two sources were used to collect data: logbooks and two semi-structured group interviews with the OTs. For each of the 13 clients in the ReWorkStroke program a logbook was kept/written, which included information on every meeting, phone call, workplace visit, time used, number of the various encounters, etc. The logbooks furthermore contained the OTs' description of actions taken/components in the program provided to each client participating in ReWork-Stroke and his/her involved stakeholders.

The two OTs were interviewed by one of the authors (AHF) regarding their experiences of delivering the ReWork-Stroke program. They were interviewed together when half of the clients had completed ReWork-Stroke and again at the end of the project when all clients had completed the program. The interviews were digitally recorded and transcribed verbatim resulting in 70 pages of text.

\subsection{Data analysis}

The structure for reporting the delivery of the ReWork-Stroke program in this process evaluation was inspired by recommendations in the Template for Intervention Description and Replication (TIDieR) [15]. The text from the logbooks, i.e., the quantitative process data, corresponds to "how, where, when and how much" in the TIDieR structure.

A deductive qualitative content analysis [16] of the text in the logbooks was applied. In the first step, the text was read through by three of the authors (UJ, $\mathrm{GE}, \mathrm{AÖN}$ ) in order to become familiar with the data. Thereafter, the text was organized according to the nine components in the preparation and work-trial phases in the program [9]. Next, meaning units were identified in the text for each component and labelled with codes using words that were close to the text. Finally, the codes from all components were compared and condensed into five categories based on similarities in the OTs' understandings of the mechanisms of impact in the ReWork-Stroke program.

The verbatim transcripts of the semi-structured interviews were analyzed by two other authors $\mathrm{TH}$, AHF) using qualitative content analysis [16]. The interviews were first read through by both authors and thoroughly discussed in order to get an overall grasp of the content of the material and identify meaning units. Thereafter, the material was divided into condensed meaning units which were coded in a manner that was close to the participants' own words. 
When merging the codes into categories, the five categories found in the analysis of the logbooks served as a framework. Based on the condensed meaning units, an additional category emerged from this analysis.

\subsection{Ethics}

This study was approved by the Regional Ethical Review Board in Stockholm, Sweden (2012/1010-31, 2018/939-32).

\section{Results}

The analysis of quantitative data as well as qualitative data revealed generic components in the ReWork-Stroke program as well as a variation in the components related to individual needs, such as technical aids at the workplace and the involvement of other health professionals. Most of the actions for clients and involved people at the workplace were provided face-to-face, while contacts with the SSIA and general practitioners (GPs) were delivered by mail or telephone. ReWork-Stroke was mainly provided in the context of the client's workplace. The mean number of workplace visits was 8.5 , with a range of 6-12 visits, and the mean total time used for visits involving the client and involved stakeholders was 11.3 hours. Components in the program were provided both jointly to the client and stakeholders, individually to the clients, and separately to stakeholders. The time used for the individual contacts with the client varied from 1 to 9 hours. Duration of the ReWork-Stroke program varied for the clients (range: 12-68 weeks), with a mean of 31.2 weeks. Also, the number of actions taken by the OTs to provide information to the involved stakeholders varied a lot, and the mean time used for those contacts

Table 2

Process data on the ReWork-Stroke program according to items included in the TIDieR structure

\begin{tabular}{|c|c|}
\hline TIDieR items & Information about the ReWork-Stroke program \\
\hline \multicolumn{2}{|l|}{ Modes of delivery of intervention } \\
\hline \multirow[t]{2}{*}{ Face-to-face } & $\begin{array}{l}\text { Majority of provisions of OT actions for/ } \\
\text { with the clients }\end{array}$ \\
\hline & $\begin{array}{l}\text { Majority of provisions of OT actions at the workplace } \\
\text { for/with co-workers/employers and clients }\end{array}$ \\
\hline \multirow[t]{2}{*}{ Mail/telephone } & $\begin{array}{l}\text { Majority of contacts with other involved stakeholders } \\
\text { (SSIA, GP) }\end{array}$ \\
\hline & Initiation of meetings with clients and employers \\
\hline Individually & $\begin{array}{l}\text { Clients (in the preparation phase and the follow-ups at } \\
\text { workplace during work-trial) }\end{array}$ \\
\hline Group & $\begin{array}{l}\text { Meetings with clients and stakeholders involved, } \\
\text { including employers }\end{array}$ \\
\hline \multicolumn{2}{|l|}{ Location(s) where actions in the program occurred } \\
\hline Number of meetings at the rehabilitation clinic & Mean $=1.23 ;$ range $=0-4$ \\
\hline Number of visits at the workplace & Mean $=8.46 ;$ range $=6-12$ \\
\hline Total length of rehabilitation period (weeks) & Mean $=31.2 ;$ range $=12-68$ \\
\hline \multicolumn{2}{|l|}{$\begin{array}{l}\text { Total number of occasions when actions were taken by the } \\
\text { OT-coordinator and time used }\end{array}$} \\
\hline $\begin{array}{l}\text { Occasions when the coordinator interacted with the client and/or } \\
\text { other stakeholders (face-to-face or telephone) }\end{array}$ & Mean $=22.4 ;$ range $=12-36$ \\
\hline Contacts for informing other stakeholders (telephone and mail) & Mean $=7.3 ;$ range $=2-15$ \\
\hline Duration of contacts for informing other stakeholders (hours) & Mean $=4.6 ;$ range $=0.8-9.6$ \\
\hline \multicolumn{2}{|l|}{$\begin{array}{l}\text { Number of times components in the program were delivered } \\
\text { individually, both at the workplace and rehabilitation clinic }\end{array}$} \\
\hline Meetings with clients & Mean $=8.9 ;$ range $=7-12$ \\
\hline Phone contact with clients & Mean $=2.6 ;$ range $=0-5.3$ \\
\hline Duration of individual meetings or telephone contacts (hours) & Mean $=4.2 ;$ range $=1-9.1$ \\
\hline \multicolumn{2}{|l|}{$\begin{array}{l}\text { Number of times components in the program were delivered } \\
\text { individually solely at the workplace }\end{array}$} \\
\hline Meetings with clients & Mean $=8.5 ;$ range $=6-12$ \\
\hline Duration of individual meetings (hours) & Mean $=1.8 ;$ range $=0.7-5.4$ \\
\hline \multicolumn{2}{|l|}{$\begin{array}{l}\text { Number of times components in the program were delivered in } \\
\text { collaboration with other stakeholders at the workplace }\end{array}$} \\
\hline Meetings with employer and/or co-worker & Mean $=6.5 ;$ range $=2-10$ \\
\hline $\begin{array}{l}\text { Duration of meetings with employer } \\
\text { and/or co-worker (hours) }\end{array}$ & Mean $=11.3 ;$ range $($ per meeting $)=1.3-2.2$ \\
\hline
\end{tabular}


regarding a specific client was 4.6 hours. More detailed information on the quantitative process data is presented in Table 2 .

The OTs' understanding of the mechanisms of impact in the ReWork-Stroke program and their experiences of providing it were described in the following five categories: Make the client aware of the consequences of stroke for working life; Inform stakeholders about the client's specific consequences of stroke; Suggest and evaluate use of individualized strategies; Assessment, goal-setting and evaluation of the client's work ability at the workplace; Planning and follow-up of work trial. One additional category emerged from the analysis of the interviews: The coordinating role of the OT-building an alliance to create a team.

The five categories are presented in detail below. In each category, the findings based on the logbooks are presented first, followed by the OTs' experiences as narrated in the semi-structured interviews.

\subsection{Make the client aware of the consequences of stroke for working life}

The analysis of the logbooks confirmed that the OTs deliberately made an effort to make each client aware of the specific consequences of their stroke. During the preparation phase for RTW and continuously during the program the OTs addressed difficulties and discussed possible consequences of stroke with the client that could influence the client's working life. They also discussed the client's selfperceived abilities compared with before the stroke. The sorrow that many of the clients felt about the situation was expressed, as well as how to deal with the changes brought about by the stroke. Furthermore, the OTs gave advice regarding how to manage the work situation and how to plan the days to reach a balance between work, free time and rest. Realistic possibilities for an RTW plan were discussed based on the clients' consequences of stroke and the demands of the workplace. A method of dealing with the awareness of consequences of stroke was to elaborate a hands-on plan for how the client would like to present him/herself in meetings with stakeholders involved in the RTW process.

The stories told in the interviews revealed that the OTs experienced that the clients' process of discovering all the consequences that might have arisen due to the stroke was lengthy and sometimes did not appear until the person was back at work. The clients appeared to realize that their inabilities in daily life were more severe than they first thought; here, one of the OTs reflects on the clients' process:

It takes time then ... to mourn the limitations you recognize, to find new ways to handle it, test if it works, evaluate ... and also see to how long it lasts in one's working life. So ... one doesn't do that in three months. It takes a very long time.

The OTs experienced that the clients felt comfortable having their support, since it created a feeling of security.

\subsection{Inform stakeholders about the client's specific consequences of stroke}

The logbooks revealed that oral (and sometimes also written) information on the consequences of stroke for the work situation was given to the involved stakeholders. During contact with the employer, information was provided regarding specific consequences due to stroke, as well as how environmental issues could influence work ability; for example, a disorganized environment could increase fatigue. Advice was also given about how the employer could facilitate the RTW process by providing ongoing support from a co-worker working side by side with the colleague with stroke at the start of the work trial to minimize the risk of stress.

Information to employers about the consequences of the stroke was expressed by the OTs in the interviews as an important element in the program. They found it important to create an alliance with the client so as to set a strategy regarding which issues were okay to talk about at meetings with stakeholders. Sometimes this was experienced as a balancing act for the OT if the client did not want their co-workers and employers to know everything. In these cases, the OTs found it beneficial to have continuous contact with the client, as well as the employers and co-workers, in order to be able to support them step-by-step during the work trial and build a trusting relationship with employers and co-workers. One of them expressed:

But it is incredibly exciting, and you feel as though you are doing something important that this person you meet can actually benefit from, that the understanding at the workplace increases, enabling us to pave the way and give help and support to them.

As the work trial went on, the employers and coworkers asked for information about how much they 
could push their colleagues without risking a backlash or how best to support them.

\subsection{Suggest and evaluate the use of individualized strategies}

The types of strategies the OTs described in the logbooks are presented in Table 3.

Introducing strategies to handle different work tasks was considered to be a core component in the program. The OTs appreciated the opportunity to try possible strategies in the clients' work context. One of the OTs said:

It is easier when I have seen with my own eyes how it is compared to when someone explains it to me... . I can have an idea when I talk with someone, but if I am at the workplace, I can see that perhaps my idea is not possible. So, for that reason, I think it is a benefit to go there.

Sometimes the co-worker/employer proposed strategies based on their knowledge of the work tasks and the understanding of the challenges faced by their colleague with stroke. The OTs experienced the co-worker/employer as a valued resource in the rehabilitation process who played an important role in implementing strategies at the workplace. The OTs raised the necessity of using strategies to increase functioning in everyday life and improve performance of work tasks. These strategies were often based on strategies the client used before their stroke. The integration of the strategies was repeated continuously by the OTs throughout the work trial and feedback was collected regarding how the strategies

Table 3

Strategies used to address problems in the work situation

\begin{tabular}{ll}
\hline Problem & Strategy to address the problem \\
\hline Memory problems & Writing to-do list/have-done list \\
& Using reminders on cell phones \\
& Using diaries and calendars \\
& Using written instructions \\
& Checking to-do list \\
$\begin{array}{l}\text { Problems with } \\
\text { initiating activity }\end{array}$ & Use of digital applications \\
Language problems & Taking breaks \\
Fatigue & Taking a short walk \\
& Using earplugs \\
& Avoiding making \\
& decisions when stressed \\
& Reducing pace \\
Reduced simultaneous & Do one task at a time \\
capacity & \\
Physical problems & Use technical aids \\
\hline
\end{tabular}

were implemented in the work situation in recurrent meetings with the client, employer and/or co-worker, and in some cases through contact with the family.

\subsection{Assessment, goal-setting and evaluation of the client's work ability at the workplace}

The logbooks reported use of the Assessment of Work Characteristics (AWC) [17] together with the client and the employer and/or co-worker to specifically assess the demands of work tasks. The result of the AWC assessment served as a basis for choosing work tasks and evaluating the outcome of the work. At the beginning of the work trial, a plan was made to gather feedback from employers and co-workers regarding performance of work tasks, as well as number and distribution of working hours during recurrent meetings at the workplace. This feedback was a basis for decisions about possible increases in demands in work tasks, and about the extent of working hours as a preparation for returning to paid work.

The OTs reflected in the interviews on the use of the formal assessments suggested in the ReWorkStroke program. They did not see any great benefit in using the Canadian Occupational Performance Measure [18] and the Assessment of Work Performance [19] instead of performing an unstructured observation based on their extensive experience from working in the field. However, the OTs valued the possibility to observe the client at the workplace.

\subsection{Planning and follow-up of the work trial}

The process of planning and follow-up during and after the work trial had three parts, each with a different focus. Based on both logbooks and interviews, the OTs were found to be central throughout this process in initiating and coordinating all activities; this is further described in the sub-categories below.

\subsubsection{Formal planning before the work trial}

The employer, the SSIA officer and the OT negotiated setting up a work trial, including an appropriate number of working hours for the employee with stroke, which also matched the work tasks that were supposed to be accomplished. The logbooks revealed that the OTs made detailed plans during the visits to the workplace in the preparation phase in regard to how the client should be introduced to work tasks, which colleague to collaborate with and get support from when starting the work trial, and when follow-up meetings should occur. At the end of the preparation 
phase, the employer, an officer from the SSIA, the client, and the OT decided on a start date for the work trial and its content (e.g., choice of work tasks, extent and distribution of working hours, and days per week).

The OTs described during the interviews that their most important and extensive work was in the planning phase before the work trial began, as this was a complex process involving various stakeholders with diverse wishes and standpoints. The OTs expressed that they put a lot of effort into this phase to create a shared platform for all involved stakeholders, and they experienced that they had a consultative role and could share their previous experiences during this planning.

The clients sometimes strived to RTW too early, mainly because they had insufficient awareness of their difficulties after stroke. The employers always strived to have a plan for a work trial that was consistent with the demands of the workplace. The OTs seldom experienced the employers as negative, but felt they were very accurate and precise in stating what skills would be required from the client in order to start a work trial. The employers' ability to express their expectations to their employee and to the officers from the SSIA created good preconditions for a successful work trial.

\subsubsection{Follow-up and evaluate the work trial together with the employer and/or co-worker regarding choice of work task and performance, working hours, work environment, and everyday life routines}

Progress regarding work performance, from easy tasks at the start of work trial to regular work tasks as performed before the stroke, was discussed during follow-ups. Furthermore, the employer and/or co-worker and the client interchanged information on his/her work performance and why some work tasks were difficult to perform. If necessary, the OTs advised the employer on environmental adjustments at the workplace, such as creating a quiet workplace. They also ascertained the distribution of working hours over the week and whether changes were necessary.

The OTs provided information about the ongoing work trial to other stakeholders who seldom took part in the planning, such as the SSIA representatives and GPs. Furthermore, they contacted the SSIA about various benefits and contacted the Swedish Public Employment Service, speech and language therapists and healthcare providers about technical aids.
Contacts were also made with close relatives to receive their information on how everyday life progressed after starting the work trial.

The OTs also met with clients to check whether the work trial and increased demands at work affected their level of fatigue and/or their everyday life in general. For some, the OTs gave support when the client felt discouraged and perceived working life as tough. During these individual meetings they talked about how the change to a new daily schedule in everyday life worked, such as the incorporation of fitness training and time for rest to minimize fatigue, resting before driving home from work, etc.

The OTs expressed in the interviews that establishing a plan for the interaction with the employer and the co-worker was not always easy. They often found that the co-workers did not have time for follow-ups and discussions. The OTs met them briefly when they visited the client at work. However, sometimes the employer contacted the OT by phone to discuss issues they felt were hard to handle, such as work tasks that appeared to be too difficult. When the employers did not want to talk openly with their employee about these issues, it was difficult for the OTs to know how to handle this information. Only a few clients had a specific person assigned as a tutor during the work trial; mostly they had a close co-worker who gave extra support. Based on these experiences, the OTs highly recommended that the client to have a coworker who was formally assigned the task of being a tutor.

\section{I think of those I have met, there is actually no one who had a tutor at work. Instead it has been a close co-worker who has functioned as a tutor and it has worked out well, so when you have a close co-worker who you know from before and trust and feel safe with, then it is really good.}

Often, the difficulties at work did not become obvious until several months had passed. At that point in time, the work trial was soon to end. This was experienced as unfortunate, as the RTW process must adhere to rules and regulations from the SSIA-e.g., the time frame allowed for a work trial-and this could be an obstacle for RTW.

The OTs also experienced that the follow-ups during work trials reflected the employer's attitude toward their employee and the workload at the workplace. If the workload was heavy, the employer had less tolerance with the employee. This was described by one of the OTs: 
He maybe needs some help... and they are not quite prepared to give him that, and they are not prepared to give him the extra time and it does not work. And I can also understand the boss. If he is allowed to continue maybe the others quit because the workload becomes too heavy. It is not easy. Not when it is such a pressure as it is at many workplaces.

\subsubsection{Formal follow-up after the work trial}

The logbooks included information on the formal meeting at the end of the work trial. This might include clarifications regarding remaining difficulties in the performance of work tasks necessary to start working for a salary, in which case negotiations with the SSIA on extending the work trial could occur. If paid work was a possibility, a decision was taken regarding working hours, their distribution, start date, and work tasks. The OTs afterwards informed the GP as he/she seldom attended this formal meeting.

At the end of the three-month work trial, the OTs organized meetings with the client, the employer, and an officer from the SSIA. The OTs expressed that a key aspect during these meetings was the social insurance regulations. The time limit of a three-month work trial was often perceived to be too short and created huge challenges for the employer and the employee with stroke. Even so, the OTs said they often found suitable solutions for how the work trial and the gradual RTW process could proceed beyond the first three months.

\subsection{The coordinating role of the OT-building an alliance to create a team}

The OTs viewed their own role in the ReWorkStroke program as bringing all involved stakeholders together. Their priority was to build an alliance with the client. They also saw themselves as a player in the team consisting of the client and the employer. Sometimes they had to be the bridge between them to create the team, while for other clients the team was already in place. With a team built upon trust and a shared goal, the OTs found that it was easier to talk about sensitive topics during the work trial:

It was a woman I met who felt such pressure from the boss. She said: 'I should try working more hours now, should try that work task, but Ifeel like I am not there yet.' And she had some problems with talking to the boss herself. So then we did that together.
On these occasions the OTs were a bridge between the client and the employer. The OTs made efforts to create a shared understanding of the various perspectives and achieve a practical and fruitful work trial for the client by merging all involved stakeholders' issues, wishes and regulations.

\section{Discussion}

This study aimed at exploring and describing how the ReWork-Stroke program was provided by the OTs, as well as their experiences of providing the program. The process evaluation of the implementation of ReWork-Stroke showed that the program was highly flexible, allowing actions to be designed to meet each individual client's unique needs; in other words, the program was person-centered. The predominant components in the program, and those emphasized by the OTs in the logbooks and interviews as mechanisms of impact, were: building an alliance with the client; locating intervention at the workplace; information about stroke to all involved; coordination and collaboration with all stakeholders involving negotiating a plan for the work trial; and follow up of the work trial at the workplace with all involved stakeholders. Previous research has shown that components associated with positive effects on work ability were interventions supplied at the workplace [4] as well as support from and collaboration with the management [20]. Nevertheless, the Swedish guidelines for rehabilitation after stroke [21], are still lacking advice concerning work-related rehabilitation. The ReWork-Stroke program might be the first step in developing an evidence-based program for RTW in Sweden.

The ReWork-Stroke program was mainly delivered at the workplace and comprised coordination with and provision of information regarding the process to all stakeholders (Table 2). Most of the program was provided through face-to-face contacts in the clients' work environment. These meetings provided an understanding about how the work tasks and the environment could either support or hinder the client in the process of returning to work, as also previously outlined by Sandqvist et al. [17]. There is strong evidence that interventions at the workplace directed at, for example, adaptation of work tasks in combination with coaching, are associated with a successful RTW process after stroke [1].

The results, based on the logbooks, underline the importance of designing and providing the components in the program according to the unique 
client and his or her specific needs and demands at work, such as environmental and work-task-specific conditions; this finding is in line with previous studies $[2,3]$. This factor was also evident in the variation and similarity in how the components in ReWork-Stroke were delivered among the individuals, in terms of where, with whom, how often, and mode of delivery (Table 2). These findings indicate that there is a need for both generic and specific person-centered components when planning a work trial.

In the ReWork-Stroke program, the OTs continually had contact with stakeholders in face-to-face meetings, by phone, or via mail. The results underline the benefit of face-to-face meetings, but these meetings are time consuming and therefore might be costly to implement in regular services. On the other hand, meetings at the workplace, as mentioned earlier, can contribute a variety of useful information and opportunities for knowledge sharing among stakeholders. These kinds of opportunities can be difficult to achieve in other ways and are therefore beneficial from a long-term perspective. The OTs also optimized the RTW process for the individual clients by providing information from meetings to stakeholders who did not attend. This coordination was found to be effective for clients with other diagnoses [22] as well. In the further development of the program, different technical solutions might be added as a support. This support can include information on stroke and stroke consequences for managers, clients and close relatives available on a webpage, and reminders sent via SMS on strategies to use in the work environment for clients and co-workers. Delivering rehabilitation interventions via information and communication technology was in a recent review suggested to be a valid option as similar results were found in comparison to face-to-face interactions [23]. In future studies, the effectiveness of these technical solutions should be evaluated, as well as the significance of face-to-face meetings when these cannot be replaced by technological means.

The results from the logbooks revealed that one of the components provided to all stakeholders in the ReWork-Stroke program was the information given regarding the consequences of stroke, and strategies on how to handle these in the specific work situation. Providing this knowledge during the RTW process was found to be important both for clients with stroke [10] and stakeholders [8, 11, 24], creating a shared understanding. This was also reported in a study of person-centered activities of daily living intervention after stroke, where knowledge sharing between the client and the therapist was found to be a cornerstone of the rehabilitation process [25]. This was also the case in RTW-processes for people with common mental disorders [26].

A variety of skills and knowledge were used by the coordinating OTs to analyze the demands of the work tasks in the specific work environment in relation to the clients' present work (dis)ability. Shaw and co-workers [27] as well as Hansen Falkdal and Hörnqvist Bylund [28] explained that a coordinator needs to be skilled in many areas. One of the more difficult tasks for the OTs was finding/using strategies to work with the clients' reduced insight regarding their own limitations, which has been described by Foy et al. [29] as a crucial factor for RTW success. Thus, a component in the ReWork-Stroke was the discussion between the client and the OT concerning the consequences of stroke for the work situation. In collaboration, a strategy was formulated about how to present this information to the co-worker/manager and other stakeholders. In a Finnish study on RTW for persons with burnout, the importance of discussing the consequences of burnout for the work situation was also highlighted. This openness about the consequences could facilitate providing the right support at work [30].

The mapping of strengths and limitations after stroke was in some cases performed using formal assessments and in other cases through more informal observation, when the OTs relied on their experience and considered informal observations to be more relevant. For an OT without this specific knowledge about stroke or experience in making workplace visits to observe clients performing their ordinary work tasks, it would be more appropriate to use formal assessments, which also allow a proper evaluation of the intervention. Further, in the preparation phase, use of a goal-setting assessment would be recommended to gain information to enhance person-centeredness in delivering ReWork-Stroke. Furthermore, in the implementation phase, the purpose of each component in the program needs to be thoroughly discussed with new OTs to ensure that all generic components are provided as intended, emphasized also for coordinators in RTW for common mental disorders [26]. That also goes for the component in ReWorkStroke involving contact with relatives/family about everyday life outside work and the availability of occupational health services when needed. According to the logbooks, this component in the program was adhered to less than others, but overall the OTs provided the program as intended. 


\subsection{Methodological considerations}

This study used a case study design. One advantage of a case study design is the option to use data from different sources, such as interviews and logbooks, as well as quantitative registrations providing different perspectives on the program studied. The case, the functioning of the person-centered rehabilitation program ReWork-Stroke, how it was provided, and the experience of providing the program all benefitted from being described and explored using different data sources, as they are multifaceted and it is not possible to measure them using statistical analyses. Further, the use of the structure from TIDieR has added clarity in exploring and reporting the results of the provision of the program and is recommended by others [15].

This study is based on the logbooks and the experiences of providing the ReWork-Stroke by only two OTs, which might limit the ability to generalize the results. However, the program was provided to 13 clients during a two-year period, which generates a variation of experiences of clients, consequences of stroke, workplaces, work tasks, and collaborations with managers, co-workers, and SSIA officers, all of which strengthens the results of the study.

Furthermore, to ascertain the trustworthiness of the results [16], the researchers started by reading the interviews and the logbooks repeatedly to get a good understanding of the text. During the analyses they went back and forth in the text to make sure the results were in accordance with the data. The researchers worked in pairs with data from logbooks and interviews, respectively, but the emerging results were discussed by the whole group. To ensure the credibility of the study, triangulation of data sources was used. Using data from different sources, in this case from interviews and logbooks, increased the ability to verify particular details that have been identified through one of the sources with another [31].

\section{Conclusion}

The predominant components in the program that were understood by the OTs as the mechanisms of impact during the delivery of the ReWork-Stroke were: building an alliance with the client; focusing intervention at the workplace by providing information about stroke to all involved; assigning a coworker as tutor for the client during the work trial; and coordination and collaboration with all stakeholders, including negotiating a plan for the work trial and subsequent follow-up at the workplace. The findings confirmed the need for individually tailored content in the program, as demonstrated by the differences in delivered components and length of the preparation phase among the clients. A key factor in returning to work for the person with stroke was recognizing and coming to terms with their new/current work ability. This process of identifying the new situation at work also applied to employers and co-workers in terms of the changes in work ability of their employees/colleagues.

The OTs performed analyses of demands in relation to work ability and contextual resources at the workplace gave an understanding of several aspects of work for those involved, forming the basis for suggestions/implications for removing obstacles in the work situation. The delivery and evaluation of the ReWork-Stroke program could benefit from using a more structured approach regarding assessment embedded in the person-centered program designed for each client and his/her work situation. In the further development of ReWork-Stroke, support from technical solutions might be added and evaluated to see if it can replace other types of meetings/contacts between stakeholders.

\section{Acknowledgments}

The authors gratefully acknowledge the OTs who provided the ReWork-Stroke program for sharing their experiences. The study was supported by the Centre for Research and Development, Uppsala University/Region Gävleborg, Sweden; the Doctoral School in Health Care Sciences at Karolinska Institutet, Sweden; the regional agreement on medical training and clinical research between Uppsala County Council and the Uppsala University hospital (ALF), Sweden; and the Swedish Stroke Association.

\section{Conflict of interest}

None to report.

\section{References}

[1] Donker-Cools BH, Daams JG, Wind H, Frings-Dresen MH. Effective return-to-work interventions after acquired brain injury: A systematic review. Brain Inj. 2016;30(2):113-31. http://doi.org/10.3109/02699052.2015.1090014. 
[2] Trexler LE, Parrott DR, Malec JF. Replication of a Prospective Randomized Controlled Trial of Resource Facilitation to Improve Return to Work and School After Brain Injury. Arch Phys Med Rehabil. 2016;97(2):204-10. http://doi.org/10.1016/j.apmr.2015.09.016.

[3] Ntsiea MV, Van Aswegen H, Lord S, Olorunju SS. The effect of a workplace intervention program on return to work after stroke: a randomised controlled trial. Clin Rehabil. 2015;29(7):663-73. http://doi:10.1177/0269 215514554241.

[4] Oakman J, Neupane S, Proper K, Kinsman N, Nygård C. Workplace interventions to improve work ability: A systematic review and meta-analysis of their effectiveness. Scand J Work Environ Health. 2018;44(2):134-46. http://doi:10.5271/sjweh.3685.

[5] Riksstroke. Ett år efter stroke 1-årsuppföljning 2015livssituation, tillgodosedda behov och resultat av vårdens och omsorgens insatser [Riks-Stroke, the Swedish Stroke Register: 1-year follow-up 2015-life situation, fulfilled needs and results of health care services interventions for those suffering stroke during 2014]; 2016. [Internet]; [cited 2021 January 17]. Available from: www.riksstroke. org/.../2016/11/Riksstroke_1-årsuppföljning_2015.pdf.

[6] Rosengren A, Giang KW, Lappas G, Jern C, Toren $\mathrm{K}$, Bjorck L. Twenty-four-year trends in the incidence of ischemic stroke in Sweden from 1987 to 2010. Stroke. 2013;44(9):2388-93. http://doi:10.1161/strokeaha. 113.001170 .

[7] Craig P, Dieppe P, Macintyre S, Michie S, Nazareth I, Petticrew M. Developing and evaluating complex interventions: the new Medical Research Council guidance. BMJ. 2008;337:a1655. http://doi.org/10.1136/bmj.a1655.

[8] Hellman T, Bergstrom A, Eriksson G, Hansen Falkdal A, Johansson U. Return to work after stroke: important aspects shared and contrasted by five stakeholder groups. Work. 2016;55(4):901-11. http://doi.org/10.3233/WOR-162455.

[9] Johansson U, Hellman T, Öst Nilsson A, Eriksson G. The ReWork-Stroke rehabilitation programme described by use of the TIDieR checklist. Scand J Occup Ther. 2020:1-9. http://doi.org/10.1080/11038128.2020.1790654.

[10] Öst Nilsson A, Eriksson G, Johansson U, Hellman T. Experiences of the return to work process after stroke while participating in a person-centred rehabilitation programme. Scand J Occup Ther. 2017;24(5):349-56. http://doi.org/10.1080/11038128.2016.1249404.

[11] Öst Nilsson A, Eriksson G, Asaba E, Johansson U, Hellman T. Being a co-worker or a manager of a colleague returning to work after stroke: a challenge facilitated by cooperation and flexibility. Scand J of Occup Ther. 2019:110. http://doi.org/10.1080/11038128.2018.1526318.

[12] Moore GF, Audrey S, Barker M, Bond L, Bonell C, Hardeman W, et al. Process evaluation of complex interventions: Medical Research Council guidance. BMJ. 2015;350:h1258. http://doi.org/10.1136/bmj.h1258.

[13] Chambers DA, Glasgow RE, Stange KC. The dynamic sustainability framework: addressing the paradox of sustainment amid ongoing change. Implement Sci. 2013;8:117. http://doi.org/10.1186/1748-5908-8-117.

[14] Yin RK. Case study research: design and methods. London: SAGE; 2014.

[15] Hoffmann TC, Glasziou PP, Boutron I, Milne R, Perera $\mathrm{R}$, Moher $\mathrm{D}$, et al. Better reporting of interventions: template for intervention description and replication (TIDieR) checklist and guide. BMJ. 2014;348:g1687. http:// doi.org/: 10.1136/bmj.g1687.
[16] Graneheim UH, Lundman B. Qualitative content analysis in nursing research: concepts, procedures and measures to achieve trustworthiness. Nurse Educ Today. 2004;24(2): 105-12. http://doi:10.1016/j.nedt.2003.10.001.

[17] Sandqvist J. Evidensbaserad bedömning av arbetsförmåga. Assessment of Work Performance (AWP) och Assessment of Work Characteristics (AWC). Ergoterapeuten. 2017;1:62-6.

[18] Law M, Baptiste S, McColl M, Opzoomer A, Polatajko $\mathrm{H}$, Pollock N. The Canadian occupational performance measure: an outcome measure for occupational therapy. Can J Occup Ther. 1990;57:82-7. http://doi:10.1177/0008 41749005700207.

[19] Fan CW, Taylor RR, Ekbladh E, Hemmingsson H, Sandqvist J. Evaluating the Psychometric Properties of a Clinical Vocational Rehabilitation Outcome Measurement: The Assessment of Work Performance (AWP). OTJR (Thorofare N J). 2013;33(3):125-33. http://doi:10.3928/15394492-201 30614-01.

[20] Ilmarinen J. From Work Ability Research to Implementation. Int J Environ Res Public Health. 2019;16(16):2882. https://doi:10.3390/ijerph16162882.

[21] Socialstyrelsen. Nationella riktlinjer för vård vid stroke [National Board of Health and Welfare guidelines for stroke care] 2018. [Internet]; [cited 2021 January 17]. Available from: https://www.socialstyrelsen.se/publi kationer2018/2018-3-11.

[22] Dekkers-Sánchez PM, Wind H, Sluiter JK, Frings-Dresen MHW. What promotes sustained return to work of employees on long-term sick leave? Perspectives of vocational rehabilitation professionals. Scand J Work Environ Health. 2011;37(6):481-93. http://www.jstor.org/stable/23064883.

[23] Zonneveld M, Patomella A-H, Asaba E, Guidetti S. The use of information and communication technology in healthcare to improve participation in everyday life: a scoping review. Disabil Rehabil. 2019;1-8. http://doi:10.1080/09638288.2019.1592246.

[24] Coole C, Radford K, Grant M, Terry J. Returning to work after stroke: perspectives of employer stakeholders, a qualitative study. J Occup Rehabil. 2013;23(3):406-18. http://doi:10.1007/s10926-012-9401-1.

[25] Ranner M, von Koch L, Guidetti S, Tham K. Client-centred ADL intervention after stroke: occupational therapists' experiences. Scand J Occup Ther. 2016;23(2):81-90. http://doi:10.3109/11038128.2015.1115549.

[26] Holmlund L, Hellman T, Engblom M, Kvak L, Sandman L, Törnkvist L, et al. Coordination of return-to-work for employees on sick leave due to common mental disorders: facilitators and barriers. Disabil Rehabil.2020; http://doi:10.1080/09638288.2020.1855263.

[27] Shaw W, Hong QN, Pransky G, Loisel P. A literature review describing the role of return-to-work coordinators in trial programs and interventions designed to prevent workplace disability. J Occup Rehabil. 2008;18(1):2-15. https://doi.org/10.1007/s10926-007-9115-y.

[28] Sveriges kommuner och Landsting: Hälso- och sjukvårdens funktion för koordinering i sjukskrivnings- och rehabiliteringsprocessen. En litteraturstudie. [The Swedish association of local authorities and regions; The function of healthcare for coordination in the process of sick leave and rehabilitation. A review.] Stockholm: SKL; 2015.

[29] Foy CM. Long term efficacy of an integrated neurological and vocational rehabilitation programme for young adults with acquired brain injury. J Occup Rehabil. 2014;24(3):533-42. http://doi:10.1007/s10926-013-9488-z. 
[30] Karkkainen R, Saaranen T, Rasanen K. Return-to-Work Coordinators' Practices for Workers with Burnout. J Occup Rehabil. 2019;29(3):493-502. http://doi:10.1007/s10926018-9810-x.
[31] Shenton A. Strategies for ensuring trustworthiness in qualitative research projects. Education for Information. 2004;22:63-75. http://doi:10.3233/EFI-2004-22201. 